OPEN ACCESS

Edited by: Jie Hu,

The Ohio State University,

United States

Reviewed by:

Marte Karoline Råberg Kjøllesdal,

Norwegian Institute of Public Health

(NIPH), Norway

Yingchen Wang,

Shandong Youth University of Political

Science, China

*Correspondence:

Samir KC

kcsamir@gmail.com

Specialty section:

This article was submitted to Life-Course Epidemiology and Social

Inequalities in Health,

a section of the journal

Frontiers in Public Health

Received: 29 July 2021 Accepted: 03 January 2022

Published: 11 February 2022

Citation:

Wu J, KC S and Luy M (2022) The

Gender Gap in Life Expectancy in

Urban and Rural China, 2013-2018.

Front. Public Health 10:749238.

doi: 10.3389/fpubh.2022.749238

\section{The Gender Gap in Life Expectancy in Urban and Rural China, 2013-2018}

\author{
Jinjing Wu ${ }^{1}$, Samir $K C^{1,2 *}$ and Marc Luy ${ }^{3}$ \\ ${ }^{1}$ Asian Demographic Research Institute, Shanghai University, Shanghai, China, ${ }^{2}$ International Institute for Applied Systems \\ Analysis (IIASA), Wittgenstein Centre for Demography and Global Human Capital (IIASA, OeAW, University of Vienna), \\ Laxenburg, Austria, ${ }^{3}$ Vienna Institute of Demography (OeAW), Wittgenstein Centre for Demography and Global Human \\ Capital (IIASA, OeAW, University of Vienna), Vienna, Austria
}

Background: Gender differences in mortality are embedded within mortality transitions. Rural residents generally lag behind their urban counterparts in the transitions. The study objective is to identify major causes of death that drive gender differences in mortality in urban and rural China.

Methods: We use age-, gender-, urban-rural- and cause-specific mortality data (2013-2018) derived from the national mortality surveillance system that covered about $24 \%$ of the Chinese population. We apply Arriaga's method to decompose age- and cause-specific contributions to the gender gap in life expectancy at birth. Analyses are stratified by urban-rural residence.

Results: Women had a higher life expectancy at birth than men in both urban and rural areas. Cancers, cardiovascular disease, external causes, and respiratory disease accounted for more than 90\% of the gender gap in both areas during 2013-2018. In urban areas, the gender gap decreased from 5.17 years in 2013-2015 to 4.98 years in 2016-2018. In rural areas, the gender gap stayed rather constant (2013-2015: 5.68 years; 2016-2018: 5.65 years). Traffic accidents, among external causes, contributed the most to decreasing the gender gap (urban: -0.07 years; rural: -0.10 years), especially in the 0-44 age group. However, the decrease in the gender gap was counteracted by an increase in the gender gap attributable to ischemic heart disease (urban: +0.05 years; rural: +0.08 years) and lung cancer (urban: +0.02 years; rural: +0.05 years) in older age groups. The gender gap attributable either to cerebrovascular disease or to chronic lower respiratory disease decreased in urban areas but increased in rural areas.

Conclusions: The urban-rural variations in the cause-specific contributions to the gender gap in China suggest the necessity of implementing urban-rural-specific interventions to improve population health and health equity.

Keywords: gender gap, life expectancy, cause of death, urban-rural difference, China

\section{INTRODUCTION}

Women generally live longer than men due to biological, social-structural, psychosocial, and behavioral factors (1), except in a few of the world's poorest countries where men still outlive women (2). However, the gender gap in life expectancy at birth (hereafter, "the gender gap"), embedded within mortality transitions, varies over place and time (2). Decomposing the gender gap and its 
variations by cause of death will help to identify which causes of death need closer monitoring and reveal opportunities to improve gender equity in longevity.

Evidence from Western developed countries shows that cardiovascular disease (CVD), one of the most common noncommunicable diseases (NCD), contributes a substantial portion of the gender gap $(3,4)$. Most Western developed societies have witnessed a decrease in the gender gap since the 1980s (3-7), which parallels a steady decrease in the CVD mortality in the West $(8,9)$.

Cigarette smoking is a prominent risk factor for developing NCD including CVD, lung cancer, and chronic lower respiratory disease (10). Decreased smoking among men and increased smoking among women explain a substantial portion of the decrease in the gender gap in Western developed countries (3, 11-13). However, the extent to which the decrease in the gender gap can be explained by the trends of women's and men's smoking behaviors in the course of the so-called "smoking epidemic" differs between countries (14).

In addition to NCD, traffic accidents are also a major cause of death responsible for gender differences in mortality (3). In Western industrialized countries, traffic accident mortality rates increased in the post-World War II period (1945-1970) but decreased thereafter (15). Men's greater improvements in mortality from traffic accidents over recent decades have contributed to a notable portion of the decreasing gender gap in these countries (3). Most studies on the gender gap are conducted in industrialized societies, especially in the West (3-7), providing only a partial picture of the evolving gender gap along with mortality transitions. Given varying economic development levels, health system performance, and cultural backgrounds, the evolution of the gender gap and cause-specific contributions in developing countries may differ from those of developed countries.

China, one of the world's fastest-growing economies, has experienced a rapidly growing burden of NCD and traffic accidents, accompanying the rising economic prosperity (16, 17). The rapidly growing burden of NCD in China is not only accelerated by an emerging obesity epidemic due to a nutrition transition toward increased energy intake and decreased physical activity (18); it is also driven by a rapid increase in the number of male deaths from smoking as a consequence of a high male smoking rate $(10,16)$. The male excess mortality may be increased along with the growing burden of NCD and traffic accidents as men are more likely to engage in risky behaviors including unhealthy eating, smoking, and unsafe driving than women (1, 2). However, evidence on the contributions of NCD (e.g., CVD, lung cancer, chronic lower respiratory disease) and traffic accidents to the gender gap remains limited and inconclusive in the context of China $(19,20)$.

Due to an urban-rural dual system established in the early 1950s, urban people generally have higher income and better health care access $(21,22)$. Moreover, the smoking, obesity, and NCD epidemics started in urban areas and then spread into rural areas (23-25). The urban-rural heterogeneities provide a unique opportunity to examine potential drivers (e.g., health care access, smoking, obesity) of variations in the gender gap and inform urban-rural-specific interventions that aim to improve population health and health equity. However, to the best of our knowledge, the urban-rural variations in the cause-specific contributions to the gender gap have not been addressed in the literature so far.

The main objectives of this study include (1) estimating the gender gap in China during 2013-2018 with data from the Chinese national mortality surveillance system, (2) investigating how the gender gap changed from 2013-2015 to 2016-2018, (3) clarifying the cause-specific contributions to the gender gap, with a focus on CVD, lung cancer, chronic lower respiratory disease, and traffic accidents, and (4) examining whether the cause-specific contributions varied by urban-rural residence.

\section{MATERIALS AND METHODS \\ Data, Sample and Variables}

The Chinese government established a nationally and provincially representative mortality surveillance system in 2013 by combining the vital registration system of the National Health Commission of China that was built in the 1950s and the disease surveillance points system of the Chinese Center for Disease Control and Prevention that was built in 1978 (26). In 2013, the national mortality surveillance system comprised 605 surveillance points in total, with each point representing an entire district or county (26). Out of the 605 surveillance points, 158 and 113 points were retained from the disease surveillance points system and the vital registration system, respectively, while the rest were newly added in 2013 (26). The system covered 31 provinces and more than 0.3 billion people, making up 24\% of the Chinese population (26). To ensure representativeness at the provincial level, each county or district is selected using an iterative method involving multistage stratification that considers the sociodemographic characteristics of the population (26). More details can be found in (26).

The national project team excludes the surveillance points with unreasonably low mortality from the estimation of national mortality rates. Among the surveillance points established before 2013 , the points having a mortality rate of below $4.5 \%$ are excluded; among the points newly added in 2013, the points having a mortality rate of below $5.0 \%$ are excluded (27). Thus, the mortality data reported come from 432, 491, 491, 499, 509, and 512 out of 605 mortality surveillance points in 2013, 2014, 2015, 2016, 2017, and 2018, respectively (27).

From the China Health Statistics Yearbooks, we obtain the age-, gender-, urban-rural- and cause-specific mortality rates derived from the national mortality surveillance system (28). We do not include the mortality data collected before 2013 in our analyses as the data is not nationally representative and thus not comparable to the data collected since 2013. The China Health Statistics Yearbooks do not report the number of respondents and deaths in the national mortality surveillance system. Therefore, it is not possible to provide uncertainty estimates. 


\section{Cause of Death}

The causes of death are classified by the tenth revision of the International Statistical Classification of Diseases and Related Health Problems (ICD-10). Consistent with (19), we include seven chapters of ICD-10 (i.e., cancer; cardiovascular disease; external causes; respiratory disease; digestive disease; infectious disease; endocrine, nutritional, and metabolic disease) and thirty-two subchapters into our analyses. These chapters and subchapters cover the most common causes of death in China (29) and are most relevant to the gender gap $(19,20)$. In addition, we include two categories that cover other causes and unspecified causes, respectively.

\section{Urban-Rural Residence}

The sampling unit of the national mortality surveillance system is the district or county (26). In China, districts and counties are at the same administrative level under prefecture-level cities; there are urban and suburban districts, while counties cover the majority of rural areas (30). To be consistent with prior studies (31), we classify districts as urban areas and counties as rural areas.

\section{Life Expectancy at Birth}

Life expectancy at birth is one of the most widely used summary measures of mortality rates across all age groups observed at a specific point of time (32). To facilitate a comparison of our results with that of previous studies $(19,20,33,34)$, we estimated life expectancy at birth by gender. It can be interpreted as the average number of years that a newborn baby is expected to live, with the assumption that the observed age-specific mortality rates remain unchanged in the future (32).

\section{Statistical Analyses Life Table Techniques}

Life tables by gender and urban-rural residence are constructed using all-cause mortality rates. We use standard life table techniques to estimate the life expectancy at birth by gender and urban-rural residence (35). We use age categories that were 0 , 1-4, 5-year age groups starting with 5-9 years up until 80-84, and the last open age interval $85+$. More details about life table construction can be found in (34).

\section{Arriaga's Decomposition Method}

Arriaga's decomposition method has been widely used to decompose differences in life expectancy between men and women by age and cause $(19,20,33,34)$. More details about the development of decomposition methods can be found in (36) and (37). To facilitate a comparison of our estimates to the findings of previous studies, we use Arriaga's method to decompose the gender gap by age and further by cause of death $(38,39)$.

A gender difference in mortality in all age groups except for the oldest age group has three different effects on total life expectancy: direct, indirect, and interaction effects (38). The gender difference in mortality in the oldest age group only has a direct effect on total life expectancy.
The gender difference in life expectancy attributable to the age group $\mathrm{x}$ to $\mathrm{x}+\mathrm{n}$ is estimated as follows:

$$
\begin{aligned}
\Delta_{x}= & {\left[\frac{l_{x}^{\text {Men }}}{l_{0}^{\text {Men }}} \times\left(\frac{L_{x}^{\text {Women }}}{l_{x}^{\text {Women }}}-\frac{L_{x}^{\text {Men }}}{l_{x}^{\text {Men }}}\right)\right]+\left[\frac{T_{x+n}^{\text {Women }}}{l_{x+n}^{\text {Women }}}\right.} \\
& \left.\times \frac{\frac{l_{x}^{\text {Men }} l_{x+n}^{\text {Women }}}{l_{x}^{\text {Women }}}-l_{x+n}^{\text {Men }}}{l_{0}^{\text {Men }}}\right]
\end{aligned}
$$

We assume that women have a lower mortality rate than men between ages $\mathrm{x}$ and $\mathrm{x}+\mathrm{n}$. In formula (1), $\Delta x$ is the contribution of the age group $\mathrm{x}$ to $\mathrm{x}+\mathrm{n}$ to the gender difference in life expectancy at birth. $l_{0}^{\mathrm{Men}}$ is the number of men surviving to age 0 (i.e., $100,000) . l_{x}^{M e n}$ and $l_{x}^{\text {Women }}$ are the numbers of people surviving to the exact age $\mathrm{x}$ of 100,000 people in men and women, respectively. $L_{x}^{M e n}$ and $L_{x}^{\text {Women }}$ represent the number of person-years lived between ages $\mathrm{x}$ and $\mathrm{x}+\mathrm{n}$ in men and women, respectively. $l_{x+n}^{\text {Women }}$ is the number of women surviving to the exact age $\mathrm{x}+\mathrm{n} . T_{x+n}^{\text {Women }}$ is the number of person-years lived from age $x+n$ to the oldest age group in women.

The first term on the right-hand side of formula (1) captures the direct effect. The direct effect measures the gender difference in the number of person-years lived between ages $\mathrm{x}$ and $\mathrm{x}+\mathrm{n}$ due to women's lower mortality rate in this age group within the age interval.

The second term on the right-hand side of formula (1) corresponds to the sum of the indirect and interaction effects.

There is an indirect effect resulting from additional female survivors at the end of the age interval, $x+n$, because of women's lower mortality rate between ages $x$ and $x+n$. The additional female survivors at the age $\mathrm{x}+\mathrm{n}$ will pass through successive age groups and then result in an additional number of person-years lived, contributing indirectly to the overall gender gap (38).

Both the direct and indirect effects only consider the gender difference in mortality between ages $\mathrm{x}$ and $\mathrm{x}+\mathrm{n}$. However, gender differences in mortality exist in almost every age group. The additional female survivors at the age $\mathrm{x}+\mathrm{n}$ will be exposed to lower (or higher) mortality rates than their male counterparts across successive age groups after the age $\mathrm{x}+\mathrm{n}$. The interaction effect results from the combination of the additional female survivors at the age $\mathrm{x}+\mathrm{n}$ due to women's lower mortality rate between ages $\mathrm{x}$ and $\mathrm{x}+\mathrm{n}$ and the lower (or higher mortality rates at older age groups (38).

We further decompose the gender gap by cause of death, with the assumption that the contribution of each cause to the gender difference in life expectancy at a specific age group is proportional to the contribution of each cause to the gender difference in the all-cause mortality rates in the same age group (33). The gender gap attributable to a specific cause between ages $x$ and $x+n$ is estimated as follows:

$$
\Delta_{x}^{i}={ }_{x} \times \frac{p_{x}^{i, \text { Women }}-p_{x}^{i, \text { Men }}}{r_{x}^{\text {Women }}-r_{x}^{\text {Men }}}
$$

In formula $2, \Delta_{x}^{i}$ is the contribution of the cause $i$ to the gender gap between ages $\mathrm{x}$ and $\mathrm{x}+\mathrm{n}$. $r_{x}^{\text {Women }}$ and $r_{x}^{\text {Men }}$ represent women's and men's mortality rates between ages $\mathrm{x}$ and $\mathrm{x}+\mathrm{n}$, respectively. 
TABLE 1 | Gender gap in life expectancy at birth ${ }^{a}$ in 2013-2018, 2013-2015, and 2016-2018 by urban-rural residence.

\begin{tabular}{lcc}
\hline & Urban & Rural \\
& Gender gap in life expectancy at birth, years \\
$2013-2018$ & 5.08 & 5.66 \\
$2013-2015$ & 5.17 & 5.68 \\
$2016-2018$ & 4.98 & 5.65 \\
& Changes in gender gap in life expectancy at birth from \\
From 2013-2015 & $2013-2015$ to 2016-2018, years \\
to 2016-2018 & -0.19 & -0.03 \\
\end{tabular}

aThe gender gap in life expectancy at birth is equal to women's life expectancy at birth minus men's life expectancy at birth.

$p_{x}^{i, \text { Women }}$, and $p_{x}^{i, \text { Men }}$ are women and men's mortality rates from cause $\mathrm{i}$ between ages $\mathrm{x}$ and $\mathrm{x}+\mathrm{n}$, respectively.

To avoid the strong fluctuation in the gender gap in each year, we estimate the cause-specific contributions to the gender gap for the whole period of 2013-2018 instead of estimating the contributions for each year. To estimate the change in the cause-specific contributions to the gender gap, we compare the cause-specific contributions to the gender gap during 2016-2018 with the contributions during 2013-2015. As the number of respondents and deaths in the national mortality surveillance system is not publicly available, we calculate the mean mortality rates over a period by averaging the year-specific mortality rates. As the samples of the national mortality surveillance system in different years are close in size and represent the same study population, averaging the year-specific mortality rates is relatively valid (40).

\section{RESULTS}

\section{The Gender Gap in Life Expectancy at Birth During 2013-2018}

Life expectancy at birth by gender and urban-rural residence is reported in Supplementary Table S1. Table 1 reports the gender gap in life expectancy at birth during 2013-2018 by urban-rural residence and compares the gender gap in 2013-2015 to the gender gap in 2016-2018. The estimates of the gender gap are positive, showing that women had a higher life expectancy at birth than men in both urban and rural areas during 2013-2018. Moreover, our estimates indicate that the gender gap may be larger in rural areas than in urban areas. As shown in Table 1, the gender gap in urban areas decreased from 5.08 years in 20132015 to 4.98 years in 2016-2018. The gender gap in rural areas stayed rather constant.

\section{Age-Specific Contributions to the Gender Gap During 2013-2018}

For clarity, Table 2 reports the gender gap in five broad age groups (i.e., the $0-44,45-59,60-74,75-84$, and $85+$ age groups) during 2013-2018 by urban-rural residence. As shown in Table 2, the 60-84 age group contributed about half of the gender gap
TABLE 2 | Age-specific contributions to the gender gap in life expectancy at birth during 2013-2018.

\begin{tabular}{lccccc}
\hline & \multicolumn{2}{c}{ Urban } & & \multicolumn{2}{c}{ Rural } \\
\cline { 2 - 3 } & Years & $\%$ & & Years & $\%$ \\
\hline $0-44$ & 0.82 & 16.06 & 1.19 & 20.98 \\
$45-59$ & 1.19 & 23.40 & 1.31 & 23.06 \\
$60-74$ & 1.98 & 39.02 & 1.91 & 33.73 \\
$75-84$ & 0.80 & 15.70 & & 0.94 & 16.60 \\
$85+$ & 0.30 & 5.81 & 0.32 & 5.63 \\
\hline Total & 5.08 & 100.00 & 5.66 & 100.00 \\
\hline
\end{tabular}

in both areas. The 45-59 age group accounted for above $20 \%$ of the gender gap and ranked second in contributing to the gender gap. The 0-44 age group may account for a larger proportion of the gender gap in rural areas than in urban areas. More details about the age-specific contributions to the gender gap during 2013-2018 are reported in Supplementary Table S2.

\section{Cause-Specific Contributions to the Gender Gap During 2013-2018}

Table 3 presents the cause-specific contributions to the gender gap by urban-rural residence during 2013-2018. Cancer, cardiovascular disease, external causes, and respiratory disease accounted for above $92 \%$ of the gender gap in both areas. Cerebrovascular disease contributed the most to the gender gap, especially in rural areas (urban: 0.86 years; rural: 1.02 years), followed by lung cancer (urban: 0.69 years; rural: 0.58 years), IHD (urban: 0.57 years; rural: 0.59 years), and chronic lower respiratory disease (urban: 0.43 years; rural: 0.45 years). Liver cancer and stomach cancer accounted for above 0.42 and 0.25 years of the gender gap, respectively. Traffic accidents resulted in a larger gap in rural areas than urban areas (urban: 0.28 years; rural: 0.48 years).

\section{Cause-Specific Contributions to the Change in the Gender Gap From 2013-2015 to 2016-2018}

Figure 1 presents the age- and cause-specific contributions to the change in the gender gap from 2013-2015 to 20162018 by urban-rural residence. For clarity, we only report the contributions from cerebrovascular disease, IHD, lung cancer, chronic lower respiratory disease, and traffic accidents in the four broad age groups (i.e., 0-44, 45-59, 60-74, 75-84, and $85+$ age groups). More details about the cause-specific contributions to the change in the gender gap are reported in Supplementary Tables S3, S4.

Traffic accidents were the main contributor to decreasing the gender gap in both areas from 2013-2015 to 2016-2018 (urban: -0.07 years; rural: -0.10 years) (Supplementary Tables S3, S4). Figure 1 further shows that the decrease in the gender gap attributable to traffic accidents was mainly concentrated in the $0-44$ age group. 
TABLE 3 | Cause-specific contributions to the gender gap in life expectancy at birth $^{\mathrm{a}}$ during 2013-2018 by urban-rural residence.

\begin{tabular}{|c|c|c|c|c|}
\hline & \multicolumn{2}{|c|}{ Urban } & \multicolumn{2}{|c|}{ Rural } \\
\hline & Years & $\%$ & Years & $\%$ \\
\hline Cancer & 1.71 & 33.74 & 1.72 & 30.37 \\
\hline Malignant tumor & 1.71 & 33.66 & 1.72 & 30.31 \\
\hline Nasopharyngeal cancer & 0.03 & 0.53 & 0.03 & 0.53 \\
\hline Esophagus cancer & 0.20 & 3.89 & 0.22 & 3.96 \\
\hline Stomach cancer & 0.25 & 4.94 & 0.28 & 5.03 \\
\hline Colorectal cancer & 0.09 & 1.80 & 0.06 & 1.12 \\
\hline Liver cancer & 0.42 & 8.24 & 0.49 & 8.62 \\
\hline Lung cancer & 0.69 & 13.68 & 0.58 & 10.28 \\
\hline Breast cancer & -0.16 & -3.17 & -0.12 & -2.08 \\
\hline Cervical cancer & -0.09 & -1.71 & -0.09 & -1.65 \\
\hline Bladder cancer & 0.04 & 0.78 & 0.03 & 0.54 \\
\hline Leukocythemia & 0.03 & 0.52 & 0.03 & 0.49 \\
\hline Cardiovascular disease & 1.61 & 31.70 & 1.81 & 32.03 \\
\hline Heart disease & 0.70 & 13.75 & 0.74 & 13.04 \\
\hline Chronic rheumatic heart disease & -0.01 & -0.19 & -0.01 & -0.16 \\
\hline Hypertensive cardiopathy & 0.04 & 0.88 & 0.06 & 1.07 \\
\hline Ischemic heart disease & 0.57 & 11.15 & 0.59 & 10.46 \\
\hline Cerebrovascular disease & 0.86 & 16.87 & 1.02 & 18.04 \\
\hline Other hypertensive diseases & 0.03 & 0.64 & 0.04 & 0.63 \\
\hline External causes & 0.63 & 12.51 & 1.06 & 18.66 \\
\hline Traffic accidents & 0.28 & 5.55 & 0.48 & 8.55 \\
\hline Accidental fall & 0.10 & 1.95 & 0.14 & 2.55 \\
\hline Drowning & 0.06 & 1.28 & 0.11 & 1.90 \\
\hline Suicide & 0.04 & 0.73 & 0.06 & 1.08 \\
\hline Respiratory disease & 0.60 & 11.87 & 0.56 & 9.88 \\
\hline Pneumonia & 0.11 & 2.18 & 0.06 & 0.98 \\
\hline Chronic lower respiratory disease & 0.43 & 8.39 & 0.45 & 8.02 \\
\hline Digestive disease & 0.17 & 3.30 & 0.19 & 3.42 \\
\hline Gastric and duodenal ulcer & 0.02 & 0.45 & 0.03 & 0.52 \\
\hline Intestinal obstruction & 0.01 & 0.13 & 0.01 & 0.10 \\
\hline Liver disease & 0.10 & 2.06 & 0.12 & 2.14 \\
\hline Infectious disease & 0.11 & 2.17 & 0.12 & 2.20 \\
\hline Tuberculosis & 0.03 & 0.68 & 0.04 & 0.72 \\
\hline Hepatitis & 0.04 & 0.87 & 0.05 & 0.90 \\
\hline AIDS & 0.01 & 0.28 & 0.01 & 0.24 \\
\hline Endocrine, nutritional \& metabolic disease & 0.03 & 0.67 & -0.01 & -0.17 \\
\hline Diabetes & 0.03 & 0.57 & -0.01 & -0.22 \\
\hline Other causes $^{b}$ & 0.17 & 3.29 & 0.16 & 2.87 \\
\hline Unspecified causes of death & 0.04 & 0.77 & 0.03 & 0.75 \\
\hline Total & 5.08 & 100.00 & 5.66 & 100.00 \\
\hline
\end{tabular}

a We included seven chapters and thirty-two subchapters of ICD-10 in the estimation of cause-specific contributions to the gender gap. The selection of causes of death is consistent with a prior study (19) to facilitate a comparison between our study and the prior study. Each chapter contains several subchapters. We did not include all subchapters into our analyses. Therefore, the sum of the gender gap attributable to each subchapter within a specific chapter is not necessarily equal to the gender gap attributable to the chapter.

${ }^{b}$ The category of other causes includes 1) diseases of the blood and blood-forming organs and certain disorders involving the immune mechanism, 2) mental, behavioral and neurodevelopmental disorders, 3) diseases of the nervous system, 4) diseases of the musculoskeletal system and connective tissue, 5) diseases of the genitourinary system, pregnancy, childbirth and the puerperium, 6) certain conditions originating in the perinatal period, and 7) congenital malformations, deformations and chromosomal abnormalities.
IHD (urban: +0.05 years; rural: +0.08 years) was one of the main contributors to the increase in the gender gap in both areas (Supplementary Tables S3, S4). We saw a notable increase in the gender gap attributable to this cause in the 45-74 age groups in both areas (Figure 1). However, in urban areas, the gender gap attributable to this cause decreased in the $75-84$ and $85+$ age groups (Figure 1). In rural areas, the $0-44,75-84$, and $85+$ age groups had a modest increase in the gender gap attributable to this cause (Figure 1).

Lung cancer (urban: +0.02 years; rural: +0.05 years) was the other main contributor to the increase in the gender gap in both areas (Supplementary Tables S3, S4). As shown in Figure 1, in urban areas, the gender gap attributable to this cause had a notable increase in the 60-74 age group. However, it was partly offset by a slight decrease in the gender gap due to this cause in the other age groups except for the $85+$ age group. In rural areas, there was a notable increase in the gender gap due to this cause in the 60-74 age group. In contrast to urban areas, this cause resulted in a slight increase in the gender gap in the other age groups except for the $0-44$ age group.

The gender gap attributable to cerebrovascular disease decreased in urban areas but increased in rural areas (urban: -0.02 years; rural: +0.02 years) (Supplementary Tables S3, S4). According to Figure 1, although this cause increased the gender gap in the 60-74 age group in urban areas, it decreased the gender gap in the other age groups, especially in the $75-84$ age group. In rural areas, it resulted in a slight decrease in the gender gap in the 0-44 and 75-84 age groups, which cannot offset the increase in the gender gap due to this cause in the 45-59, 60-74, and 85+ age groups.

The gender gap due to chronic lower respiratory disease decreased in urban areas but increased in rural areas (Supplementary Tables S3, S4). As shown in Figure 1, in urban areas, the gender gap attributable to this cause decreased in the 45-59 and 75+ age groups and remained stable in the other age groups. However, in rural areas, this cause increased the gender gap in all the age groups, especially the $85+$ age group.

According to Supplementary Tables S3, S4, cervical cancer, breast cancer, stomach cancer, and drowning also decreased the gender gap in both urban and rural areas, while colorectal cancer and diabetes increased the gender gap. The gender gap attributable to liver cancer decreased in urban areas but remained stable in rural areas. The gender gap due to accidental falls remained stable in urban areas but increased in rural areas.

\section{DISCUSSION}

This study adds to the literature by assessing the cause-specific contributions to the gender gap over the recent period in China, a newly industrialized country, and identifying the urban-rural differentials in the cause-specific contributions. During 20132018, the gender gap was 5.08 years in urban areas and 5.66 years in rural areas. The gender gap decreased from 5.17 years in $2013-$ 2015 to 4.98 years in $2016-2018$ in urban areas but remained rather constant in rural areas. 


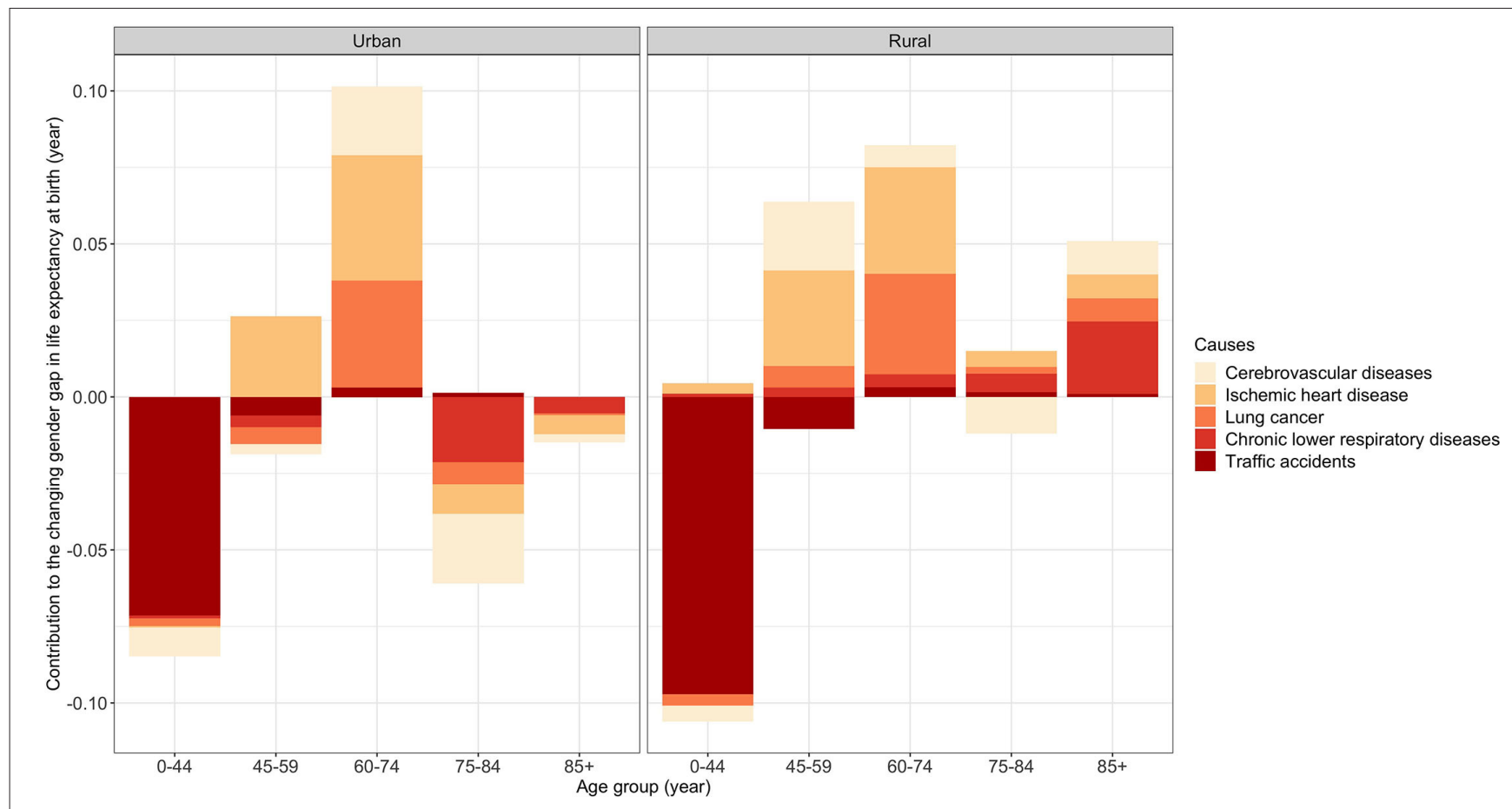

FIGURE 1 | Age- and cause-specific contributions to the changing gender gap in life expectancy at birth from 2013-2015 to $2016-2018$ by urban-rural residence.

Our results indicate that CVD, cancers, external causes, and respiratory disease were four major categories of causes of death responsible for the gender gap during 2013-2018 in both urban and rural areas, which is consistent with a growing burden of NCD and traffic accidents observed in China $(16,17)$.

IHD, ranking as the second leading cause of death among Chinese over the observation period (Supplementary Table S5 and Supplementary Figure S1), accounted for a substantial proportion of the gender gap in both areas. The gender gap attributable to IHD increased from 2013-2015 to 2016-2018, especially in rural areas. Consistently, the gender gap attributable to IHD increased in South Korea during 1992-2005 (33). However, there has been a reverse trend in most high-income Western societies, where men have experienced a greater IHD mortality decrease than women over recent decades $(3,4)$.

China is probably at an earlier stage of the transition in mortality from CVD than most developed countries. A steady decrease in the mortality of CVD including IHD and cerebrovascular disease over past decades in the West suggests that these countries have stepped into a new stage of the mortality transition $(8,9)$. However, in China, the mortality of IHD has increased over recent years, although the mortality of cerebrovascular disease has decreased (41). As men have a more pronounced increase in the IHD mortality than women (41), it is of no surprise that the gender gap attributable to IHD increased over the observation period.

The increasing gender gap attributable to IHD may be partly due to an emerging obesity epidemic in China $(16,18)$. On the one hand, women may generally have a lower level of exposure to unhealthy eating associated with obesity than men $(42,43)$. On the other hand, men may have a greater susceptibility to the adverse effects of the emerging obesity epidemic due to the moderating effects of sex steroids on cardiovascular outcomes $(44,45)$. However, the gender differences in the levels of exposure and susceptibility to the obesity epidemic and their roles in determining the gender gap remain to be tested in future studies.

Lung cancer, one of the most common cancers among Chinese people (Supplementary Table S5 and Supplementary Figure S1), also accounted for a substantial portion of the gender gap. Furthermore, lung cancer increased the gender gap from 2013-2015 to 2016-2018, especially in rural areas, which was contrary to the declining gender gap attributable to lung cancer over recent decades observed in Western developed countries $(3,4)$. But the upward trend observed in our study is consistent with the results obtained from Shanghai during 1999-2018 (20) and South Korea during 1992-2005 (33). However, Le et al. (19) showed that the contribution of lung cancer to the gender gap had ups and downs in Chinese cities during 2005-2010. One possible explanation for the inconsistent findings between (19) and ours is the different observation periods. Furthermore, we used data from the national mortality surveillance system that covered 31 provinces, while Le et al. (19) based their analyses on data from dozens of Chinese cities (19).

In many Western developed nations, a convergence in cigarette smoking and smoking-attributed mortality (e.g., lung cancer and IHD mortality) between men and women explains a substantial portion of the decrease in the gender gap that began in 
the early 1980s (3, 11-13). In China, however, gender differences in cigarette smoking have been increased $(10,46,47)$. Under the influences of Confucian patriarchal values, the female smoking prevalence remains low and has been decreased across successive birth cohorts $(10,46,47)$. Unfavorably, the male smoking prevalence remains high and has had no notable decrease across cohorts $(10,46,47)$. Furthermore, younger male cohorts have initiated cigarette smoking at an earlier age and consumed more cigarettes per smoker than older male cohorts, indicating greater future hazards of cigarette smoking for Chinese men $(10,47)$. As cigarette smoking has long been recognized as the leading risk factor for deaths from lung cancer and IHD (10), the rising gender differences in the levels of exposure to smoking in the cohort succession $(10,47)$ may explain why lung cancer and IHD increased the gender gap in both areas.

China has not yet seen the full hazards of cigarette smoking on mortality (10). The contribution of smoking-attributed mortality to the gender gap remains to be investigated in the future when the smoking epidemic steps into a more advanced stage. Furthermore, whether the gender differences in smoking will be narrowed in China (48), as it has been narrowed in Western developed nations, and result in a decrease in the gender gap attributable to smoking-related mortality decades later also requires to be investigated in future studies.

Traffic accidents also contributed a notable portion of the gender gap over the observation period in both urban and rural areas. From 2013-2015 to 2016-2018, this cause of death made the greatest contribution to reducing the gender gap. The narrowing effect of traffic accidents on the gender gap is consistent with the findings from Canada for 1970-2000 and South Korea for 1992-2005. The decreasing gender gap attributable to traffic accidents may be due to improvements in transport regulations, traffic infrastructure, trauma rescue, and hospital treatment $(49,50)$. These improvements may have led to a more pronounced decrease in the mortality from traffic accidents among men than among women, as the former generally drive more kilometers, are more likely to have unsafe driving, and have a higher initial traffic accident mortality rate than the latter (50).

Our estimates indicate that the gender gap may be smaller in urban areas than in rural areas. Furthermore, there was a notable decrease in the gender gap from 2013-2015 to 2016-2018 in urban areas, which is consistent with the decreasing gender gap observed in most developed societies (3-7). However, the gender gap remained rather constant in rural areas. Lung cancer, IHD, cerebrovascular disease, and chronic lower respiratory disease were responsible for the different trends of the gender gap observed in urban and rural areas.

Rural areas had a more pronounced increase in the gender gap due to lung cancer and IHD than urban areas. One speculative explanation is the urban-rural differences in the smoking epidemic (10). Although the smoking epidemic started earlier in urban than in rural areas, rural men have caught up with urban men in cigarette smoking and had a higher smoking prevalence at least since the mid-1980s (23). Another possible explanation is the urban-rural differences in the obesity epidemic, as obesity is a crucial risk factor of getting IHD (16). Although the obesity epidemic started in urban areas, rural residents have been catching up to their urban counterparts in body mass index in recent decades (24). This might further explain why the increase in the gender gap due to IHD may be more pronounced in rural areas than in urban areas.

Additionally, the gender gap attributable either to cerebrovascular disease or chronic lower respiratory disease decreased in urban areas but increased in rural areas over the observation period. The different findings from urban and rural areas may due to the unequal health care access between urban and rural areas. Rural people generally lag behind their urban peers in adopting upgraded surgical treatments and medications for cerebrovascular disease and chronic lower respiratory disease due to the lower availability and affordability of health care resources in rural areas (51). For example, the mortality from obstructive pulmonary disease (COPD), a main type of chronic lower respiratory disease, has remarkably decreased in China since the early 1990s due to improved COPD diagnosis and management (52). But compared with their urban counterparts, rural residents with COPD have poorer awareness of their diagnosis, more severe conditions, are less likely to seek medical advice, and more likely to die from COPD, given that they generally have less access to health care than their urban peers (53). However, more epidemiological studies that consider both gender and urban-rural heterogeneities are needed to advance our understanding of the relationship between health care access and gender differences in mortality.

A rise in the burden of cervical cancer and breast cancer in Chinese women also narrowed the gender gap in both urban and rural areas. The incidence and mortality rates of breast cancer and cervical cancer among Chinese women have increased over the past decades (54-56). Similarly, breast cancer decreased the female advantage in survival in South Korea during 19922015 (33). However, cervical cancer increased the gender gap in South Korea (33), which is inconsistent with our findings. In high-income societies, the introduction of publicly funded national human papillomavirus (HPV) vaccination programs and the expansion of early cancer detection have contributed to reducing the burden of female-dominated cancers (57). Unfortunately, both the HPV vaccination rate and cervical and breast screening rates remain low in China $(58,59)$. Without the implementation of effective interventions, these femaledominated cancers may continue to reduce the female advantage in survival.

It is important to note that this study is subject to several limitations. First, our observation period is 2013-2018, which is a relatively short period. Further studies are needed to examine whether the decrease in the gender gap in urban areas will continue and whether the gender gap in rural areas will start to decrease after 2018. Second, we are not able to provide uncertainty estimates as the comprehensive data on the number of people and deaths from the national mortality surveillance system is not publicly available. Third, prior evidence showed that Arriaga's method might underestimate the importance of causes of death that are concentrated mainly at older ages (60). Thus, our estimates regarding the contribution of NCD like 
IHD, cerebrovascular disease, lung cancer, and chronic lower respiratory disease to the gender gap may be conservative. However, the limitation may be less relevant in China than it has been in Western developed countries. Because China is at an earlier stage of mortality transition than Western developed countries. Thus, NCD may account for a smaller proportion of deaths in China than in Western developed countries. Fourth, the national mortality surveillance system is subject to the under-reporting of deaths (61). We do not correct for the under-reporting bias as our estimates of the gender gap would not be biased if the under-reporting of deaths does not vary systematically by gender. Prior evidence suggested that the gender difference in the under-reporting rate of mortality is statistically insignificant in all age groups except for the 0-4 age group (61), which suggests that we may overestimate the gender gap in the $0-4$ age groups. However, the $0-4$ age group accounted for $<3 \%$ of the gender gap in both areas during 2013-2018. The mortality rate from IHD, cerebrovascular disease, lung cancer, and chronic lower respiratory disease, the main contributors to the gender gap, was very low in this age group. Therefore, we believe that the effect of the under-reporting bias on our main findings is negligible.

\section{CONCLUSION}

The gender gap decreased in urban areas but remained rather constant in rural areas from 2013-2015 to 2016-2018. CVD, cancer, respiratory disease, and external causes were the main contributors to the gender gap during 2013-2018. Traffic accidents, among external causes, contributed to most of the decrease in the gender gap from 2013-2015 to 2016-2018 in both urban and rural areas. However, IHD and lung cancer increased the gender gap in both areas, which mitigated the gender gap reduction to a large extent. Furthermore, the gender gap attributable either to cerebrovascular disease or to chronic lower respiratory disease decreased in urban areas but increased in rural areas, suggesting the necessity of implementing urbanrural-specific interventions to improve population health and health equity.

\section{REFERENCES}

1. Read JNG, Gorman BK. Gender and health inequality. Annu Rev Sociol. (2010) 36:371-86. doi: 10.1146/annurev.soc.012809.102535

2. Cullen MR, Baiocchi M, Eggleston K, Loftus P, Fuchs V. The weaker sex? Vulnerable men and women's resilience to socio-economic disadvantage. SSM-Population Health. (2016) 2:512-24. doi: 10.1016/j.ssmph.2016.06.006

3. Trovato F, Lalu N. From divergence to convergence: the sex differential in life expectancy in Canada, 1971-2000. Can Rev Soc. (2007) 44:101-22. doi: 10.1111/j.1755-618X.2007.tb01149.x

4. Sundberg L, Agahi N, Fritzell J, Fors S. Why is the gender gap in life expectancy decreasing? The impact of age-and cause-specific mortality in Sweden 19972014. Int J Public Health. (2018) 63:673-81. doi: 10.1007/s00038-018-1097-3

5. Trovato F, Heyen NB. A varied pattern of change of the sex differential in survival in the G7 countries. J Biosoc Sci. (2006) 38:391. doi: $10.1017 /$ S0021932005007212

\section{DATA AVAILABILITY STATEMENT}

Publicly available datasets were analyzed in this study. This data can be found at: https://data.cnki.net/yearbook/Single/ N2021020144.

\section{ETHICS STATEMENT}

Ethical review and approval was not required for the study on human participants in accordance with the local legislation and institutional requirements. Written informed consent from the participants' legal guardian/next of kin was not required to participate in this study in accordance with the national legislation and the institutional requirements.

\section{AUTHOR CONTRIBUTIONS}

JW and SK conceived the original idea and performed the statistical analysis. ML was invited for his important contributions regarding the contribution of smoking-attributable mortality to the urban/rural specific evolution of the gender gap in life expectancy. JW wrote the first draft of the manuscript. SK and ML revised the manuscript critically for important intellectual contents. All authors contributed to the interpretation of the results. All authors have read and approved the final version of the manuscript.

\section{FUNDING}

This research was supported by the Shanghai Social Science Foundation (2020ESH003). The funding source has no role in study design, in the collection, analysis and interpretation of data, in the writing of the paper, or in the decision to submit the paper for publication.

\section{SUPPLEMENTARY MATERIAL}

The Supplementary Material for this article can be found online at: https://www.frontiersin.org/articles/10.3389/fpubh. 2022.749238/full\#supplementary-material

6. Liu Y, Arai A, Kanda K, Lee RB, Glasser J, Tamashiro H. Gender gaps in life expectancy: generalized trends and negative associations with development indices in OECD countries. Eur J Public Health. (2013) 23:563-8. doi: 10.1093/eurpub/cks049

7. Thorslund M, Wastesson JW, Agahi N, Lagergren M, Parker MG. The rise and fall of women's advantage: a comparison of national trends in life expectancy at age 65 years. Eur J Ageing. (2013) 10:271-7. doi: 10.1007/s10433-013-0274-8

8. Vallin J, Meslé F. Convergences and divergences in mortality: a new approach of health transition. Demogr Res. (2004) 2:11-44. doi: 10.4054/DemRes.2004.S2.2

9. Grigoriev P, Meslé F, Shkolnikov VM, Andreev E, Fihel A, Pechholdova $\mathrm{M}$, et al. The recent mortality decline in Russia: beginning of the cardiovascular revolution? Popul Dev Rev. (2014) 40:107-29. doi: 10.1111/j.1728-4457.2014.00652.x

10. Chen Z, Peto R, Zhou M, Iona A, Smith M, Yang L, et al. Contrasting male and female trends in tobacco-attributed mortality in China: evidence from 
successive nationwide prospective cohort studies. Lancet. (2015) 386:1447-56. doi: 10.1016/S0140-6736(15)00340-2

11. Lopez AD, Collishaw NE, Piha T. A descriptive model of the cigarette epidemic in developed countries. Tobacco Control. (1994) 3:242. doi: 10.1136/tc.3.3.242

12. Pampel FC. Cigarette diffusion and sex differences in smoking. J Health Soc Behav. (2001) 42:388-404. doi: 10.2307/3090186

13. McCartney G, Mahmood L, Leyland AH, Batty GD, Hunt K. Contribution of smoking-related and alcohol-related deaths to the gender gap in mortality: evidence from 30 European countries. Tobacco Control. (2011) 20:166-8. doi: 10.1136/tc.2010.037929

14. Luy M, Wegner-Siegmundt C. The impact of smoking on gender differences in life expectancy: more heterogeneous than often stated. Eur J Public Health. (2015) 25:706-10. doi: 10.1093/eurpub/cku211

15. Van Beeck EF, Borsboom GJ, Mackenbach JP. Economic development and traffic accident mortality in the industrialized world, 1962-1990. Int J Epidemiol. (2000) 29:503-9. doi: 10.1093/intjepid/29.3.503

16. Yang G, Kong L, Zhao W, Wan X, Zhai Y, Chen LC, et al. Emergence of chronic non-communicable diseases in China. Lancet. (2008) 372:1697-705. doi: 10.1016/S0140-6736(08)61366-5

17. Gong P, Liang S, Carlton EJ, Jiang Q, Wu J, Wang L, et al. Urbanisation and health in China. Lancet. (2012) 379:843-52. doi: 10.1016/S0140-6736(11)61878-3

18. Popkin BM. Global nutrition dynamics: the world is shifting rapidly toward a diet linked with noncommunicable diseases. Am J Clin Nutr. (2006) 84:28998. doi: 10.1093/ajcn/84.2.289

19. Le Y, Ren J, Shen J, Li T, Zhang CF. The changing gender differences in life expectancy in Chinese cities 2005-2010. PLoS ONE. (2015) 10:e123320. doi: 10.1371/journal.pone.0123320

20. Chen H, Zhou Y, Sun L, Chen Y, Qu X, Chen H, et al. Non-communicable diseases are key to further narrow gender gap in life expectancy in Shanghai, China. BMC Public Health. (2020) 20:1-9. doi: 10.1186/s12889-020-08932-x

21. Zimmer Z, Kaneda T, Spess L. An examination of urban versus rural mortality in China using community and individual data. J Gerontol Ser B Psychol Sci Soc Sci. (2007) 62:S349-57. doi: 10.1093/geronb/62.5.S349

22. Chan KW, Wei Y. Two systems in one country: the origin, functions, and mechanisms of the rural-urban dual system in China. Eur Geograph Econ. (2019) 60:422-54. doi: 10.1080/15387216.2019.1669203

23. Weng X, Hong Z, Chen D. Smoking prevalence in Chinese aged 15 and above. Chin Med J. (1987) 100:886-92.

24. NCD Risk Factor Collaboration (NCD-RisC). Rising rural body-mass index is the main driver of the global obesity epidemic in adults. Nature. (2019) 569:260. doi: 10.1038/s41586-019-1171-x

25. Li J, Shi L, Li S, Xu L, Qin W, Wang H. Urban-rural disparities in hypertension prevalence, detection, and medication use among Chinese Adults from 1993 to 2011. Int J Equity Health. (2017) 16:1-10. doi: 10.1186/s12939-017-0545-7

26. Liu S, Wu X, Lopez AD, Wang L, Cai Y, Page A, et al. An integrated national mortality surveillance system for death registration and mortality surveillance, China. Bull World Health Organ. (2016) 94:46-57. doi: 10.2471/BLT.15.153148

27. National Center for Chronic and Non-communicable Disease Control and Prevention and National Health Commission of China. China Death Surveillance Data Sets 2014. Beijing: China Science and Technology Press (2015).

28. National Health Commission of China. China Health Statistics Yearbook. Beijing: Peking Union Medical College Press (2020).

29. Zhou M, Wang H, Zeng X, Yin P, Zhu J, Chen W, et al. Mortality, morbidity, and risk factors in China and its provinces, 1990-2017: a systematic analysis for the Global Burden of Disease Study 2017. Lancet. (2019) 394:1145-58. doi: 10.1016/S0140-6736(19)30427-1

30. Organisation for Economic Co-operation and Development (OECD). Urbanisation and Green Growth in China. In: OECD Regional Development Working Papers, No. 2013/07. Paris: OECD Publishing (2013).

31. Wang L, Cheng X, Yin P, Cheng P, Liu Y, Schwebel DC, et al. Unintentional drowning mortality in China, 2006-2013. Injury Prevent. (2019) 25:47-51. doi: 10.1136/injuryprev-2017-042713

32. Guillot M. Period versus cohort life expectancy. In: Rogers RG, Crimmins EM, editors. International Handbook of Adult Mortality.
Dordrecht: Springer (2011). p. 533-50. doi: 10.1007/978-90-481-99 96-9_25

33. Yang S, Khang YH, Chun H, Harper S, Lynch J. The changing gender differences in life expectancy in Korea 1970-2005. Soc Sci Med. (2012) 75:1280-7. doi: 10.1016/j.socscimed.2012.04.026

34. Chisumpa VH, Odimegwu CO. Decomposition of age-and cause-specific adult mortality contributions to the gender gap in life expectancy from census and survey data in Zambia. SSM-Population Health. (2018) 5:218-26. doi: 10.1016/j.ssmph.2018.07.003

35. Preston S, Heuveline P, Guillot M. Demography: Measuring and Modeling Population Processes. Malden, MA: Blackwell Publishers (2001).

36. Ponnapalli KM. A comparison of different methods for decomposition of changes in expectation of life at birth and differentials in life expectancy at birth. Demogr Res. (2005) 12:141-72. doi: 10.4054/DemRes.2005.12.7

37. Beltrán-Sánchez $\mathrm{H}$, Preston SH, Canudas-Romo V. An integrated approach to cause-of-death analysis: cause-deleted life tables and decompositions of life expectancy. Demogr Res. (2008) 19:1323. doi: 10.4054/DemRes.2008.19.35

38. Arriaga EE. Measuring and explaining the change in life expectancies. Demography. (1984) 21:83-96. doi: 10.2307/2061029

39. Arriaga EE. Changing trends in mortality decline during the last decades. In: Ruzicka L, Kane P, Guillaume W, editors. In: Differential Mortality: Methodological Issues and Biosocial Factors. Oxford: Oxford University Press (1989). p. 105-29.

40. Hansen K. The Laws of Averages E. coli. (2016). Available online at: https:// wattsupwiththat.com/2017/07/24/the-laws-of-averages-part-3-the-averageaverage/ (accessed July 15, 2021).

41. Liu S, Li Y, Zeng X, Wang H, Yin P, Wang L, et al. Burden of cardiovascular diseases in China, 1990-2016: findings from the 2016 global burden of disease study. JAMA Cardiol. (2019) 4:342-52. doi: 10.1001/jamacardio.2019.0295

42. Du WW, Zhang B, Wang HJ, Wang ZH, Su C, Zhang JG, et al. Gender difference in the association between food away-from-home consumption and body weight outcomes among Chinese adults. Public Health Nutr. (2016) 19:2984-90. doi: 10.1017/S1368980016001257

43. Song Y, Wang HJ, Dong B, Ma J, Wang Z, Agardh A. 25-year trends in gender disparity for obesity and overweight by using WHO and IOTF definitions among Chinese school-aged children: a multiple cross-sectional study. BMJ Open. (2016) 6:e011904. doi: 10.1136/bmjopen-2016-011904

44. Chung RY, Schooling CM, Cowling BJ, Leung GM. How does socioeconomic development affect risk of mortality? An age-period-cohort analysis from a recently transitioned population in China. Am J Epidemiol. (2010) 171:34556. doi: 10.1093/aje/kwp378

45. Zhao J. Changing cardiovascular disease mortality and advancing longevity: Hong Kong, Shanghai and Taipei (Ph.D. dissertation). The Australian National University (2013).

46. Hermalin AI, Lowry DS. The decline of smoking among female birth cohorts in China in the 20th century: a case of arrested diffusion? Popul Res Policy Rev. (2012) 31:545-70. doi: 10.1007/s11113-012-9239-4

47. Liu S, Zhang M, Yang L, Li Y, Wang L, Huang Z, et al. Prevalence and patterns of tobacco smoking among Chinese adult men and women: findings of the 2010 national smoking survey. J Epidemiol Commun Health. (2017) 71:154-61. doi: 10.1136/jech-2016-207805

48. Han J, Chen X. A meta-analysis of cigarette smoking prevalence among adolescents in China: 1981-2010. Int J Environ Res Public Health. (2015) 12:4617-30. doi: 10.3390/ijerph120504617

49. Li Y, Xie D, Nie G, Zhang J. The drink driving situation in China. Traffic Injury Prevent. (2012) 13:101-8. doi: 10.1080/15389588.2011.637097

50. Wang L, Ning P, Yin P, Cheng P, Schwebel DC, Liu J, et al. Road traffic mortality in China: analysis of national surveillance data from 2006 to 2016. Lancet Public Health. (2019) 4:e245-55. doi: 10.1016/S2468-2667(19) 30057-X

51. Gu HQ, Yang X, Rao ZZ, Wang CJ, Zhao XQ, Wang YL, et al. Disparities in outcomes associated with rural-urban insurance status in China among inpatient women with stroke: a registry-based cohort study. Ann Transl Med. (2019) 7:426. doi: 10.21037/atm.2019.08.125

52. Yin P, Wang H, Vos T, Li Y, Liu S, Liu Y, et al. A subnational analysis of mortality and prevalence of COPD in China from 1990 to 2013: findings from the global burden of disease study 2013. Chest. (2016) 150:1269-80. doi: 10.1016/j.chest.2016.08.1474 
53. Kurmi OP, Davis KJ, Lam KBH, Guo Y, Vaucher J, Bennett D, et al. Patterns and management of chronic obstructive pulmonary disease in urban and rural China: a community-based survey of 25000 adults across 10 regions. BMJ Open Respiratory Res. (2018) 5:e000267. doi: 10.1136/bmjresp-2017-000267

54. Kim K, Zang R, Choi SC, Ryu SY, Kim JW. Current status of gynecological cancer in China. J Gynecol Oncol. (2009) 20:72-6. doi: 10.3802/jgo.2009.20.2.72

55. Shi XJ, Au WW, Wu KS, Chen LX, Lin K. Mortality characteristics and prediction of female breast cancer in China from 1991 to 2011. Asian Pacific J Cancer Prevention. (2014) 15:2785-91. doi: 10.7314/APJCP.2014.15.6.2785

56. Lu Y, Li P, Luo G, Liu D, Zou H. Cancer attributable to human papillomavirus infection in China: burden and trends. Cancer. (2020) 126:3719-32. doi: $10.1002 / \mathrm{cncr} .32986$

57. Arbyn M, Raifu AO, Weiderpass E, Bray F, Anttila A. Trends of cervical cancer mortality in the member states of the European Union. Eur J Cancer. (2009) 45:2640-8. doi: 10.1016/j.ejca.2009.07.018

58. Malvezzi M, Carioli G, Bertuccio P, Boffetta P, Levi F, La Vecchia C, et al. European cancer mortality predictions for the year 2019 with focus on breast cancer. Ann Oncol. (2019) 30:781-7. doi: 10.1093/annon $\mathrm{c} / \mathrm{mdz} 051$

59. Bao HL, Wang LH, Wang LM, Fang LW, Zhang M, Zhao ZP, et al. Study on the coverage of cervical and breast cancer screening among women aged 35-69 years and related impact of socioeconomic factors in China, 2013. Chin J Epidemiol. (2018) 39:208-12. doi: 10.3760/cma.j.issn.0254-6450.2018. 02.014
60. Wong LP, Han L, Li H, Zhao J, Zhao Q, Zimet GD. Current issues facing the introduction of human papillomavirus vaccine in China and future prospects. Hum Vacc Immunother. (2019) 15:1533-40. doi: 10.1080/21645515.2019.1611157

61. Wang L, Wang L, Cai Y, Ma L, Zhou M. Analysis of under-reporting of mortality surveillance from 2006 to 2008 in China. Chin J Prevent Med. (2011) 45:1061-4. doi: 10.3760/ema.j.issn.0253-9624.2011.12.002

Conflict of Interest: The authors declare that the research was conducted in the absence of any commercial or financial relationships that could be construed as a potential conflict of interest.

Publisher's Note: All claims expressed in this article are solely those of the authors and do not necessarily represent those of their affiliated organizations, or those of the publisher, the editors and the reviewers. Any product that may be evaluated in this article, or claim that may be made by its manufacturer, is not guaranteed or endorsed by the publisher.

Copyright (c) 2022 Wu, KC and Luy. This is an open-access article distributed under the terms of the Creative Commons Attribution License (CC BY). The use, distribution or reproduction in other forums is permitted, provided the original author(s) and the copyright owner(s) are credited and that the original publication in this journal is cited, in accordance with accepted academic practice. No use, distribution or reproduction is permitted which does not comply with these terms. 